\title{
LETTER
}

\section{Older patients in the ICU: a cautious analysis of epidemiologic data is required}

\author{
Thomas Fassier* and Antoine Duclos \\ See related research by Roch et al., http://ccforum.com/content/15/1/R36, and related commentary by McDermid and Bagshaw, \\ http://ccforum.com/content/15/1/125
}

Recently published in Critical Care, Roch and colleagues' results have been extensively commented upon [1,2]. Indeed, such observational studies are necessary to improve our understanding of ICU older patients' outcome [2]. We plead for cautious analysis of these epidemiologic data, however, highlighting the following points.

Available studies are scarce, and are exposed to selection bias. In France, the seven main cohort studies exploring octogenarian patients' outcome so far published did not form a representative national sample [1-3]. Among the 42 participating centers, 27 were medical ICUs and 27 were located in teaching hospitals; moreover, the heterogeneous case mix across centers impaired meaningful comparisons [1-3].

Most of these data were collected several years ago, over huge periods of time - for example, the French cohorts were enrolled from 1991 to 1996 and from 2001 to 2006 [1-3]. The data were possibly biased by changes in practice occurring during this time, such as changes in triage and care recently reported in cohorts of ICU older patients [3,4].

Finally, cross-national comparisons are sensitive, exposed to cultural biases. Local end-of-life policies and insurance policies can strongly influence ICU epidemiology. Between the UK and the USA for example, the ICU admission rate varies from $1.3 \%$ to $11 \%$ among the older patients dying in hospital [5].

In order to improve the admission decision-making process for ICU older patients, we call for large multicenter cohort studies, followed over time, to obtain an accurate and updated picture of this nuanced and changing epidemiology. If we are to develop prognostic scores on such studies, we need to pay special attention to their design, to ensure their external validity.

\section{Abbreviations}

$\mathrm{ICU}$, intensive care unit.

\section{Competing interests}

The authors declare that they have no competing interests.

Published: 27 April 2011

\section{References}

1. Roch A, Wiramus S, Pauly V, Forel JM, Guervilly C, Gainnier M, Papazian L: Long-term outcome in medical patients aged 80 or over following admission to an intensive care unit. Crit Care 2011, 15:R36.

2. McDermid RC, Bagshaw SM: Octogenarians in the ICU: are you ever too old? Crit Care 2011, 15:125.

3. Lerolle N, Trinquart L, Bornstain C, Tadie JM, Imbert A, Diehl JL, Fagon JY, Guerot E: Increased intensity of treatment and decreased mortality in elderly patients in an intensive care unit over a decade. Crit Care Med 2010 38:59-64.

4. Bagshaw SM, Webb SA, Delaney A, George C, Pilcher D, Hart GK, Bellomo R: Very old patients admitted to intensive care in Australia and New Zealand: a multi-centre cohort analysis. Crit Care 2009, 13:R45.

5. Wunsch H, Linde-Zwirble WT, Harrison DA, Barnato AE, Rowan KM, Angus DC: Use of intensive care services during terminal hospitalizations in England and the United States. Am J Respir Crit Care Med 2009, 180:875-880.

doi:10.1186/cc10134

Cite this article as: Fassier T, Duclos A: Older patients in the ICU: a cautious analysis of epidemiologic data is required. Critical Care 2011, 15:421.
*Correspondence: thomas.fassier@chu-lyon.fr

EAM 4128 Santé-Individu-Société, Faculté de Médecine Laënnec, Université Lyon 1, 7-11 rue G. Paradin, 69372 Lyon Cedex 8, France 